\title{
Oxidation of carbidic carbon on a rhodium surface
}

\author{
S.N. Mikhailov ${ }^{1}$, L.C.A. van den Oetelaar, H.H. Brongersma and \\ R.A. van Santen \\ Schuit Institute of Catalysis, Eindhoven University of Technology, PO Box 513 , \\ $5600 \mathrm{MB}$ Eindhoven, The Netherlands
}

Received 21 January 1994; accepted 3 May 1994

\begin{abstract}
Different mechanisms of atomic carbon and oxygen recombination on a rhodium surface are studied with Auger electron spectroscopy (AES) and X-ray photoelectron spectroscopy (XPS). The kinetics of adsorbed carbidic carbon oxidation (carbon coverage $\theta_{\mathrm{C}} \approx 0.1-0.3 \mathrm{ML}$ ) by gas-phase oxygen that proceeds by a Langmuir-Hinshelwood reaction mechanism, provides the value of the activation energy for recombination $\left(E_{\mathrm{rec}}^{\mathrm{act}} \approx 170 \pm 20 \mathrm{~kJ} / \mathrm{mol}\right)$. $E_{\mathrm{rec}}^{\text {act }}$ depends slightly on the carbon coverage. An Eley-Rideal type of reaction was observed for adsorbed oxygen and atomic gas-phase carbon recombination which occurs in a dynamic regime. The low value found for the activation energy (near zero) is consistent with the mechanism that this exothermic reaction is too fast for energy dissipation into the substrate; the energy is mainly transferred into translational, vibrational and rotational energy of $\mathrm{CO}$.
\end{abstract}

Keywords: kinetics; carbon; oxygen; recombination; rhodium; surface characterisation; XPS; AES

\section{Introduction}

Carbon, oxygen and $\mathrm{CO}$ on a $\mathrm{Rh}$ surface is a system of fundamental and technological interest in the field of heterogeneous catalysis. Rhodium is a good catalyst for the synthesis of hydrocarbons and oxygenated compounds [1,2], and is also one of the main components of the catalyst for automobile exhaust gas cleaning [3].

Rhodium was shown to be a versatile catalyst, since it can adsorb $\mathrm{CO}$ both dissociatively and associatively [4]. Sexton and Somorjai [5] reported that $\mathrm{CO}$ adsorbs molecularly on a clean polycrystalline $\mathrm{Rh}$ foil and desorbed thermally at about $520 \mathrm{~K}$. They also observed thermal desorption of $\mathrm{CO}$ at high temperature (about $970 \mathrm{~K}$ ) from a contaminated $\mathrm{Rh}$ surface (with $\mathrm{C}$ or $\mathrm{O}$ impurities) which was supposed to be associated with a recombination of the dissociated $\mathrm{CO}$ products, adsorbed $C$ and adsorbed $O$. Later work on single crystal surfaces $\operatorname{Rh}(110)$, $\mathrm{Rh}(111)$, and $\mathrm{Rh}(100)$ indicated only molecular adsorption and desorption [6-8].

\footnotetext{
${ }^{1}$ On leave from A.F. Ioffe Institute, St. Petersburg, Russia.
} 
There is still a debate in the literature whether or not $\mathrm{CO}$ dissociation occurs on stepped Rh surfaces [9]. Studying CO adsorption on a Rh(210) surface, Rebholz et al. [9] reported that a part of molecularly adsorbed $\mathrm{CO}$ undergoes dissociation during heating $(T>420 \mathrm{~K})$. A further increase of temperature (above $500 \mathrm{~K}$ ) leads to incomplete recombination of adsorbed $\mathrm{C}$ and adsorbed $\mathrm{O}$, and a $\beta \mathrm{CO}$ desorption peak (about $570 \mathrm{~K}$ ).

Using semi-empirical quantum chemical methods, the reaction paths for $\mathrm{CO}$ dissociation on $\mathrm{Rh}(111)$ and stepped $\mathrm{Rh}(111)$ have been analysed [10,11]. The activation energy for dissociation of $\mathrm{CO}$ on smooth $\mathrm{Rh}(111)$ was found to compete with CO desorption.

Until now, there are no available experimental data for the activation energy of adsorbed $\mathrm{C}$ and adsorbed $\mathrm{O}$ recombination on a $\mathrm{Rh}$ surface. Using microscopic reversibility such information would also provide an activation energy for dissociation.

One possible mechanism of recombination was theoretically analysed on the basis of the Eley-Rideal type of reaction in which gas-phase oxygen atoms collide with atomic carbon adsorbed on metal $\mathrm{Pt}(111)$ and $\mathrm{Ni}(111)[12,13]$. The major qualitative conclusion of these studies is that the product $\mathrm{CO}$ escapes quickly from the surface with considerable internal excitation. According to this model, $\mathrm{CO}$ formation by recombination of gaseous atomic oxygen with carbon adatoms is highly exothermic. The simple comparison of the $\mathrm{C}-\mathrm{O}$ binding energy in the gas phase $(-1020 \mathrm{~kJ} / \mathrm{mol}[14])$ and the binding energy of a $\mathrm{C}$ atom on $\mathrm{Pt}(111)$ of $-480 \mathrm{~kJ} / \mathrm{mol}$ that was assumed for the interaction potential [12], gives an exothermic reaction energy of $-540 \mathrm{~kJ} / \mathrm{mol}$. Furthermore, no potential energy barrier to reaction was found [12]. CO desorbs because the energy liberated in the reaction does not dissipate within the timescale of the reaction $\left(10^{-11} \mathrm{~s}\right)$ into the substrate. The calculations in refs. $[12,13]$ showed that most of the energy (more than $90 \%$ ) is carried by the gas phase $\mathrm{CO}$ molecule in the form of translational, rotational and vibrational energy.

Another possible mechanism for carbon and oxygen recombination occurs on the basis of the Langmuir-Hinshelwood model, in which both the oxygen and carbon atoms are initially adsorbed and equilibrated (and migrated) before reacting. In this case the reaction rate can be calculated by solving the corresponding complete rate equations. As we will show this situation occurs for the reaction of adsorbed $\mathrm{C}$ atoms with thermal gas-phase $\mathrm{O}_{2}$ molecules.

We will present the results of experiments on carbon and oxygen recombination representative of a reaction within the kinetic regime in which the reaction rate constants are small compared to the rates of energy exchange (the previously discussed Langmuir-Hinshelwood reaction) and representative of a reaction in which energy exchange between reacting fragments is slow. Such a reaction can be considered to proceed in the dynamic regime.

It is known that the reactivity of surface carbonaceous intermediates in many catalytic reactions, in particular hydrogenation and oxidation, strongly depends 
on the chemical state of adsorbed carbon and the nature of the substrate $[15,16]$. The most reactive carbon is usually associated with carbidic carbon, so called because its C KVV Auger line shape is similar to that of metal carbides. The most commonly used methods of carbon deposition consist of the thermal decomposition of different carbonaceous molecules such as $\mathrm{C}_{2} \mathrm{H}_{4}, \mathrm{CH}_{4}$, and $\mathrm{CO}$ [17-20], or segregation from the bulk [20]. However, the atomic dispersion of deposited carbon is not well defined due to a high probability of clustering [21-23]. The study of a "carbidic" C layer on $\mathrm{Ni}(100)$ and $\mathrm{Ni}(111)$ made from thermal decomposition of either $\mathrm{CO}$ or $\mathrm{C}_{2} \mathrm{H}_{4}$ by ultraviolet photoelectrons, $\mathrm{C} \mathrm{K}$ electron energy loss, and C KVV Auger spectroscopy indicate the presence of $C_{2}$, and maybe $C_{3}$ clusters at the surface [23]. The minimum coverage of carbon usually deposited by hydrocarbons decomposition is about $0.3-0.5 \mathrm{ML}$ [18]. The carbonaceous deposits formed from ethylene on different metals such as $\mathrm{Pt}, \mathrm{Ir}, \mathrm{Rh}$, and a $\mathrm{Pt}-\mathrm{Rh}$ alloy investigated with SIMS and AES showed a variety of compositions and chemical states of surface carbon [24].

In the present work, it was crucial for the study of the recombination reaction of carbon and oxygen to deposit a well defined mono-atomic carbon species on a $\mathrm{Rh}$ surface. An atomic carbon source in vacuum was used to study directly the reaction of carbon and oxygen recombination. Such a kind of carbon source was used before to study low temperature interaction of isolated carbon atoms with hydrogen on Pt(111) by means of HREELS [22].

Two types of experiments will be reported. Carbon atoms deposited on a $\mathrm{Rh}$ ribbon were exposed to a gas phase of oxygen and the rate of carbon depletion by CO formation is measured with AES and XPS. This provides an example of the Langmuir-Hinshelwood reaction path. In the other experiment oxygen deposited on a $\mathrm{Rh}$ surface reacted with gas-phase carbon atoms. This provides a possibility of the Eley-Rideal reaction path.

\section{Experimental}

The experiments were carried out in an ultra-high vacuum spectrometer (Perkin Elmer, PHI 550). The characterisation of surface carbon was done by Auger electron spectroscopy (AES) and X-ray photoelectron spectroscopy (XPS).

AES is more sensitive to surface carbon relative to XPS, due to a shorter mean free path of the electrons emitted by carbon. However, the application of AES to study $\mathrm{C}$ on $\mathrm{Rh}$ is difficult due to an overlap of the Auger peaks of $\mathrm{C}$ and Rh. A simple computer program was developed to deconvolute Auger spectra. It consists of two main steps: the fitting of the $\mathrm{Rh}$ peaks in a spectrum of $\mathrm{Rh}$ with adsorbed carbon at an energy of 222 and $302 \mathrm{eV}$ with Auger peaks of pure $\mathrm{Rh}$, followed by a second step: a subtraction of an Auger spectrum used as fit (only $\mathrm{Rh}$ contribution) from a measured spectrum ( $\mathrm{C}$ and $\mathrm{Rh}$ contribution) in the energy region $240-280 \mathrm{eV}$, asso- 
ciated with the carbon Auger peak. Van Langeveld et al. [25] mentioned a similar spectrum subtraction technique.

The $\mathrm{Rh}$ sample was a polycrystalline ribbon $\left(20 \times 3 \times 0.03 \mathrm{~mm}^{3}\right)$ which could be heated resistively by a direct current. X-ray diffraction showed the preferential orientation of the (110) face. The cleaning procedure of the $\mathrm{Rh}$ sample consisted of a number of cycles of argon ion sputtering, high temperature annealing $(600-1000 \mathrm{~K})$ and flashing (about $1500 \mathrm{~K})$, and oxygen dosing at elevated temperature to remove residual carbon.

According to the phase diagram $\mathrm{Rh}-\mathrm{C}$ [26], rhodium does not form a bulk carbide phase and the solid solubility of carbon in $\mathrm{Rh}$ is very low. However, we clearly observed carbon precipitation as well as carbon diffusion from the surface into the bulk at elevated temperature. A similar result of carbon diffusion on $\mathrm{Rh}(111)$ and $\mathrm{Rh}(331)$ surfaces is reported in ref. [27].

The temperature of the $\mathrm{Rh}$ sample was measured by a chromel-alumel thermocouple and by an optical pyrometer at high temperatures.

Carbon deposition was carried out by using an atomic carbon source in vacuum existing of rhenium saturated with carbon $[21,28]$. The calibration of the carbon flux was done by monitoring the time which was necessary to achieve $1 \mathrm{ML}$ of carbon coverage associated with approximately $3.8 \times 10^{15}$ at $/ \mathrm{cm}^{2}$ [29].

\section{Results and discussion}

\subsection{CARBON DEPOSITION ON RHODIUM}

Fig. 1 shows the changes in intensity of the Auger signals of $\mathrm{C}$ and $\mathrm{Rh}$ during the deposition of carbon on a Rh surface at $300 \mathrm{~K}$, and the Auger spectra of carbon (fig. 1, $a$ and b). The mechanism of deposition, as it deduces from its kinetics, is close to a "layer by layer" mechanism. When about $80 \%$ of the surface is covered by carbon, carbon starts to be deposited as a second layer simultaneously while finishing the first layer. The sticking coefficient of carbon upon carbon and of carbon upon a metal is comparable [29]. The change in the slope (see fig. 1) should coincide with 1 ML of carbon coverage.

Fig. 1a, b present the C KVV line shapes at different times of carbon deposition. The typical "carbidic" C KVV Auger line shape (fig. 1a) could be observed at low carbon coverages $\left(\theta_{\mathrm{C}} \leqslant 0.3 \mathrm{ML}\right)[23,30]$. This result is partly in contradiction with ref. [31], where the authors could not observe a pure carbide-like structure on $\mathrm{Rh}(111)$. In the latter case the carbon deposition had been done by electron beam "cracking" of carbonaceous molecules on a Rh surface. Probably, this is the reason for the difference between the observations.

The C KVV Auger line shape at $\theta_{\mathrm{C}} \approx 1.5 \mathrm{ML}$ (fig. $1 \mathrm{~b}$ ) is considerably different from that of carbidic carbon. The carbidic line shape is associated with carbon adatoms strongly bonded to the metal surface $(\mathrm{C}-\mathrm{M})$. At higher carbon concentra- 


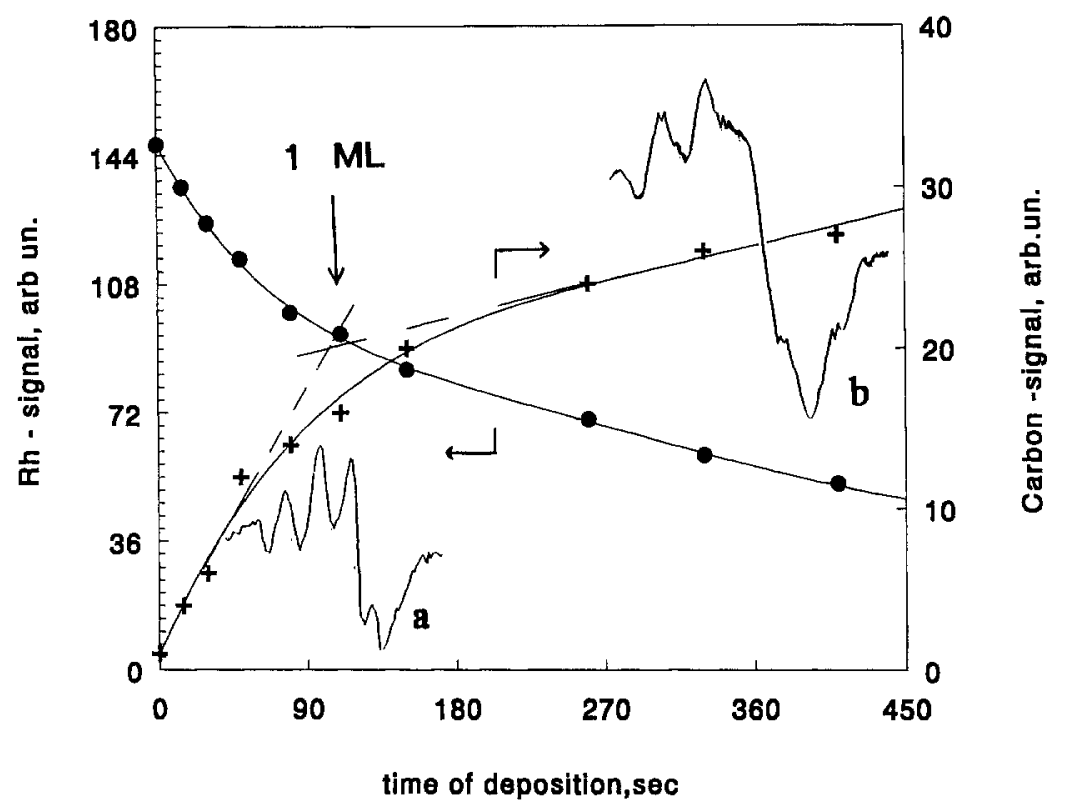

Fig. 1. Atomic carbon deposition on a Rh surface at $300 \mathrm{~K}$. The Auger signals of $\mathrm{C}(273 \mathrm{eV})(+)$ and $\mathrm{Rh}(302 \mathrm{eV})(\mathrm{O})$ are plotted as a function of deposition time. The observed $\mathrm{C}$ KVV Auger line shapes of (a) carbidic and (b) graphite-like surface carbon are depicted as well.

tion, the $\mathrm{C} \mathrm{KVV}$ line shape reflects also the presence of $\mathrm{C}-\mathrm{C}$ bonds, due to carbon-carbon interaction on the surface. A more detailed analysis of the C KVV line shape (for $\theta_{\mathrm{C}} \approx 1.5 \mathrm{ML}$ ) shows that it is close to a "graphite-like" line shape but does not exactly coincide with it. Most probably it is a mixture of different $(\mathrm{C}-\mathrm{C}$, $\mathrm{C}=\mathrm{C}, \mathrm{C} \equiv \mathrm{C}, \mathrm{C}-\mathrm{M}$ ) bonds.

Note that the change of the C KVV line shape from "carbidic" to "graphitelike" starts at $\theta_{\mathrm{C}}>0.3 \mathrm{ML}$. XPS measurements show that the $\mathrm{C} 1 \mathrm{~s}$ binding energy for carbidic carbon is about $0.5 \mathrm{eV}$ smaller than for "graphite-like" carbon. This result is in qualitative agreement with the results obtained for $\mathrm{C} / \mathrm{Ni}(111)$ [32].

To study the carbon adatom behaviour on a $\mathrm{Rh}$ surface at elevated temperature the following experiment was carried out. About $1.5 \mathrm{ML}$ was deposited at $300 \mathrm{~K}$ on the $\mathrm{Rh}$ sample. Then the sample was heated at different temperatures in the range of $300-1800 \mathrm{~K}$. During heating the XPS spectra of $\mathrm{C}$ and $\mathrm{Rh}$ were monitored. The results are shown in fig. 2. Only a slight depletion of carbon was observed up to $900 \mathrm{~K}$. At a temperature of $900-1200 \mathrm{~K}$ a decrease in $\mathrm{C}$ signal and increase in $\mathrm{Rh}$ signal was observed. The diminishing of the carbon coverage could be associated with carbon diffusion to the bulk [27] or migration to the back side of the ribbon, but not with desorption in this temperature range.

To study the kinetics of carbon oxidation on a $\mathrm{Rh}$ surface the temperature has been chosen in the range of 300-800 K, when only a slight depletion of carbon was observed. 


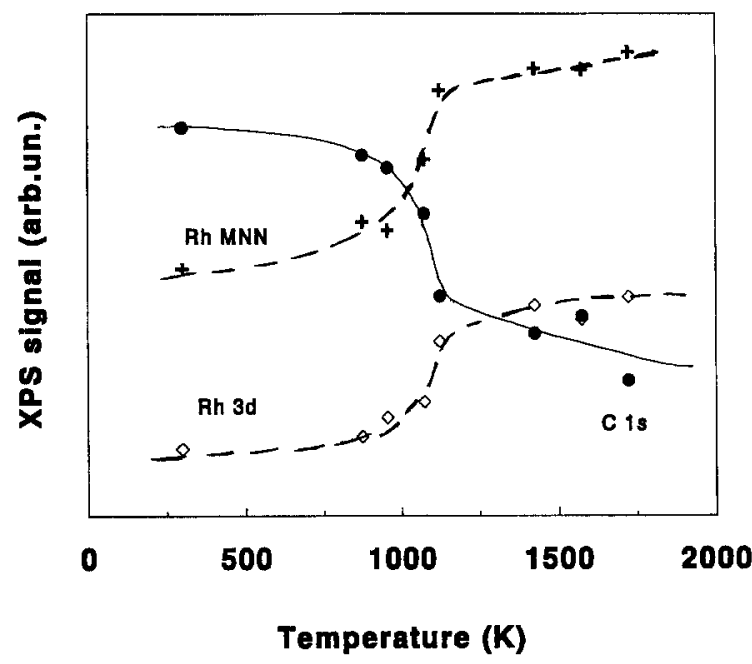

Fig. 2. Heating of the carbon adlayer (of about 1.5 ML) on a Rh surface at different temperatures (30 $\mathrm{s}$ in each point). The XPS signals for $\mathrm{C} 1 \mathrm{~s}(\bullet), \mathrm{Rh} 3 \mathrm{~d}(\diamond)$, and $\mathrm{Rh}$ MNN Auger transition ( + ) are plotted as a function of temperature.

\subsection{KINETICS OF CARBIDIC CARBON OXIDATION ON RHODIUM}

Carbidic carbon $\left(\theta_{\mathrm{C}} \leqslant 0.3 \mathrm{ML}\right)$ was deposited on $\mathrm{Rh}$ at $300 \mathrm{~K}$. After exposition to oxygen at constant oxygen pressure $\left(p\left(\mathrm{O}_{2}\right)=8 \times 10^{-8} \mathrm{mbar}\right)$ and during different exposure times at different temperatures in the range of $340-700 \mathrm{~K}$, the Auger signals of carbon, oxygen, and rhodium were monitored in situ. The experimental data are shown in fig. 3. The initial carbon coverage $\theta_{\mathrm{C}}^{0}$ was $0.1 \mathrm{ML}$.

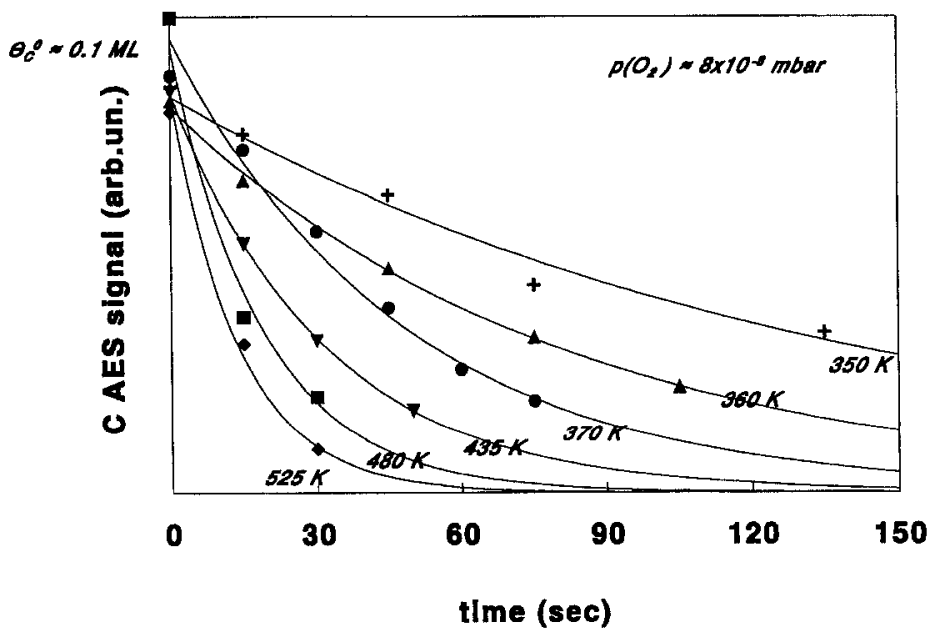

Fig. 3. Kinetics for the carbidic carbon depletion by oxygen $\left(p\left(\mathrm{O}_{2}\right)=8 \times 10^{-8} \mathrm{mbar}\right)$ at different temperatures starting with an initial carbon coverage $\theta_{\mathrm{C}}^{0}=0.1 \mathrm{ML}$. The dots are the experimental data, the lines are exponential fits. 
The carbon depletion kinetics have been measured for eight different temperatures (fig. 3 shows only six of them). The experimental curves show an exponential behavior for each measured temperature and have been fitted by the following exponential function:

$$
\theta_{\mathrm{C}}(t)=\theta_{\mathrm{C}}^{0} \exp \left[-r_{\mathrm{C}}(T) t\right]
$$

where $\theta_{\mathrm{C}}$ is the total surface carbon coverage at time $t, \theta_{\mathrm{C}}^{0}$ is the initial surface carbon coverage. The rate $r_{\mathrm{C}}(T)$ is the rate of carbon removal per unit carbon coverage,

$$
r_{\mathrm{C}}(T)=k_{0} \exp \left(-E_{\mathrm{eff}}^{\mathrm{act}} / R T\right) f\left(p\left(\mathrm{O}_{2}\right)\right)
$$

where $T$ is the temperature, $k_{0}$ is the pre-exponential factor, $E_{\text {eff }}^{\text {act }}$ is the effective activation energy for the reaction. From the exponential behaviour of the measured kinetics $r_{\mathrm{C}}(T)$ can be extracted at different temperatures. The Arrhenius plot is shown in fig. 4 for eight temperatures. Within the experimental error it shows a linear behaviour. One deduces the following parameter for $\theta_{\mathrm{C}}^{0}=0.1 \mathrm{ML}$ :

$$
E_{\text {eff }}^{\text {act }} \approx 18 \pm 3 \mathrm{~kJ} / \mathrm{mol} \text {. }
$$

The kinetics of carbon oxidation was also measured at different carbon coverages: $\theta_{\mathrm{C}}^{0}=0.1,0.15,0.25,0.3 \mathrm{ML}$ (carbidic carbon), and $0.5,1$, and $2 \mathrm{ML}$. The results of the measurements of $E_{\text {eff }}^{\text {act }}$ for carbidic carbon coverages in the range of $\theta_{\mathrm{C}}=0.1-0.3 \mathrm{ML}$ are shown in fig. 5. Within experimental error a trend of increasing $E_{\text {eff }}^{\text {act }}$ from $18 \pm 3 \mathrm{~kJ} / \mathrm{mol}$ at $\theta_{\mathrm{C}}^{0}=0.1 \mathrm{ML}$ to $23 \pm 3 \mathrm{~kJ} / \mathrm{mol}$ at $\theta_{\mathrm{C}}^{0}=0.3 \mathrm{ML}$ could be observed. This agrees with the increasing attractive interaction between $\mathrm{C}$ adatoms at increasing $\theta_{\mathrm{C}}$, when graphite-like phase formation starts.

The tendency of $E_{\text {eff }}^{\text {act }}$ to increase is found as well at $\theta_{\mathrm{C}}>0.3 \mathrm{ML}$ (for $\theta_{\mathrm{C}}^{0}=0.5 \mathrm{ML}, E_{\mathrm{eff}}^{\mathrm{act}} \approx 35 \mathrm{~kJ} / \mathrm{mol}$ ). It is associated with the formation of C-C bonds

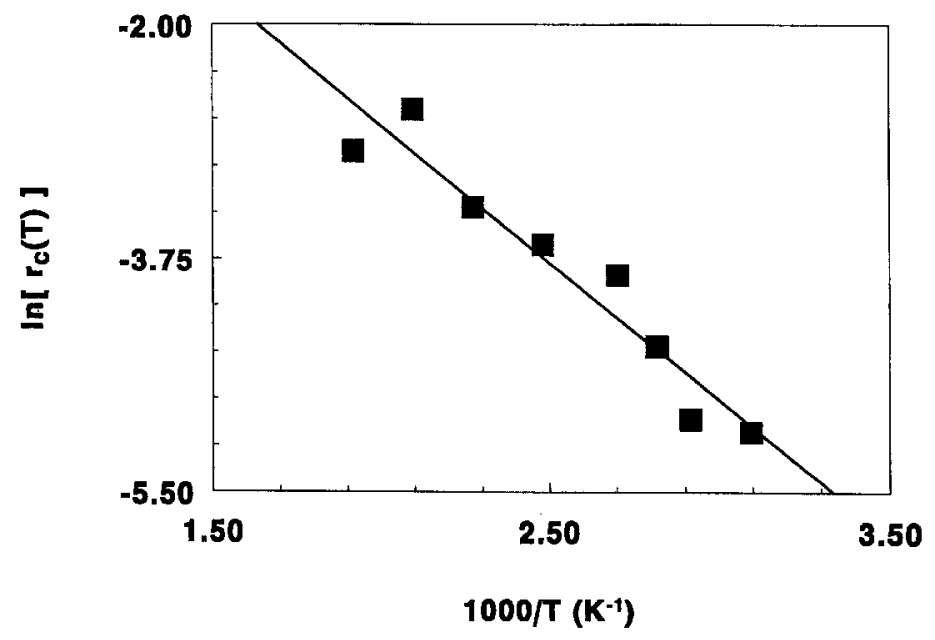

Fig. 4. Arrhenius plot of the carbidic carbon oxidation. The initial carbon coverage $\theta_{\mathrm{C}}^{0}=0.1 \mathrm{ML}$. 


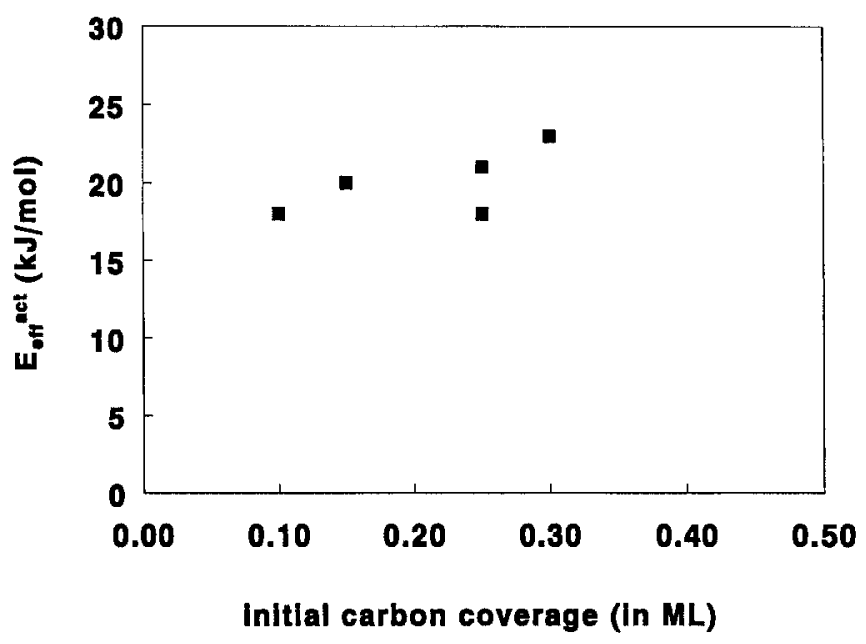

Fig. 5. Effective activation energy $\left(E_{\mathrm{eff}}^{\mathrm{act}}\right)$ of carbon oxidation as a function of carbon coverage.

due to clustering. We will discuss below a reaction model for mono-atomic carbon oxidation.

\subsection{THE LANGMUIR-HINSHELWOOD MECHANISM OF ATOMIC C OXIDATION ON \\ A Rh SURFACE}

The kinetics of carbidic carbon oxidation was measured at low constant oxygen pressure and far away from the oxygen saturation regime. The measurements of $r_{\mathrm{C}}(T)$ were not only carried out at $p\left(\mathrm{O}_{2}\right)=8 \times 10^{-8} \mathrm{mbar}$ but also at $p\left(\mathrm{O}_{2}\right)=4 \times 10^{-8}$ mbar. The experimental data can be satisfactorily explained when we assume that $\theta_{\mathrm{C}}<<1$ and $\theta_{\mathrm{O}}<<1$. The following elementary reaction steps via a Langmuir-Hinshelwood path are to be considered:

$$
\begin{aligned}
& \mathrm{O}_{2}(\mathrm{~g})+2 \mathrm{M} \rightleftharpoons 2 \mathrm{M}-\mathrm{O} \\
& \mathrm{M}-\mathrm{O}+\mathrm{M}-\mathrm{C} \rightarrow \mathrm{M}-\mathrm{CO}+\mathrm{M} \\
& \mathrm{M}-\mathrm{CO} \rightleftharpoons \mathrm{CO}+\mathrm{M} .
\end{aligned}
$$

Recently Hickman et al. [33] have demonstrated explicitly that $\mathrm{CO}$ is formed in the initial reaction step of oxygen with adsorbed carbon. Under our conditions the rate determining step is reaction (5):

$$
\begin{aligned}
& -\frac{\mathrm{d} \theta_{\mathrm{C}}}{\mathrm{d} t}=k_{\mathrm{rec}} \theta_{\mathrm{C}} \theta_{\mathrm{O}}=r_{\mathrm{C}}(T) \theta_{\mathrm{C}} \\
& \theta_{\mathrm{O}}=\frac{\left[K_{\mathrm{ads}}^{\mathrm{eq}}\left(\mathrm{O}_{2}\right) p\left(\mathrm{O}_{2}\right)\right]^{1 / 2}}{1+\left[K_{\mathrm{ads}}^{\mathrm{eq}}\left(\mathrm{O}_{2}\right) p\left(\mathrm{O}_{2}\right)\right]^{1 / 2}} \quad \text { at } \theta_{\mathrm{C}}<<1 .
\end{aligned}
$$




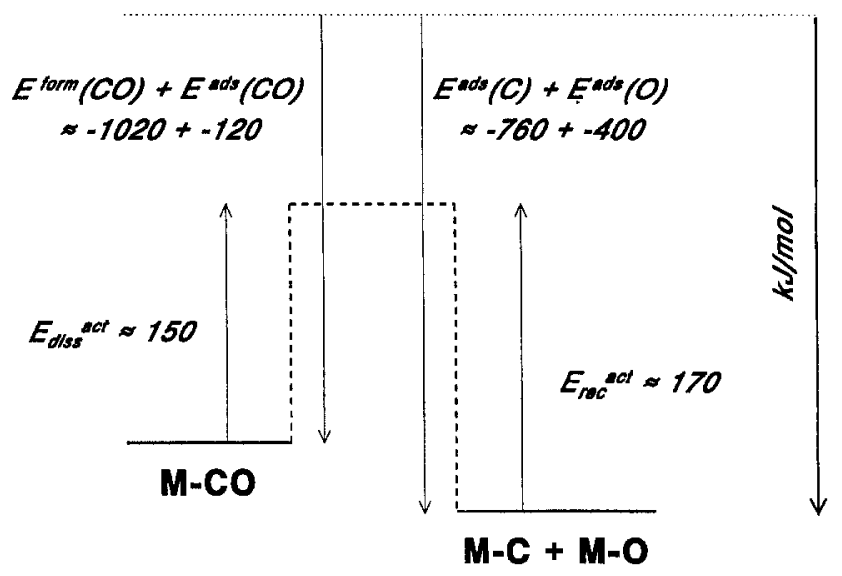

Fig. 6. Energy diagram of both the $\mathrm{C}$ and $\mathrm{O}$ recombination and $\mathrm{CO}$ dissociation on the transition metal Rh(M).

$K_{\text {ads }}^{\mathrm{eq}}\left(\mathrm{O}_{2}\right)$ is the equilibrium constant for oxygen adsorption. According to (2), (7) and (8), the effective activation energy becomes $\left(\theta_{\mathrm{O}}<1 \mathrm{ML}\right)$

$$
E_{\text {eff }}^{\text {act }}=E_{\text {rec }}^{\text {act }}+\frac{1}{2} E^{\text {ads }}\left(\mathrm{O}_{2}\right),
$$

where $E_{\mathrm{rec}}^{\text {act }}$ is the activation energy for $\mathrm{M}-\mathrm{O}+\mathrm{M}-\mathrm{C}$ recombination, $E^{\text {ads }}\left(\mathrm{O}_{2}\right)$ is the heat of dissociative oxygen adsorption.

The heat of oxygen adsorption $E^{\text {ads }}\left(\mathrm{O}_{2}\right)$ on $\mathrm{Rh}(110)$ is of the order of $-300 \mathrm{~kJ} /$ mol [34]. From the measured value of $E_{\text {eff }}^{\text {act }}$ equal to $20 \mathrm{~kJ} / \mathrm{mol}$, it gives for $E_{\text {rec }}^{\text {act }}$ a value of the order of $170 \mathrm{~kJ} / \mathrm{mol}$.

Fig. 6 shows the energy diagram corresponding to the recombination reaction and the reverse reaction: $\mathrm{CO}$ dissociation. With respect to their gas-phase atomic state, the energy of adsorption of atomic oxygen and atomic carbon is given by

$$
E(\mathrm{C}+\mathrm{O})=E^{\mathrm{ads}}(\mathrm{C})+E^{\mathrm{ads}}(\mathrm{O}) .
$$

With respect to the same state, the energy of molecular adsorption of CO equals

$$
E(\mathrm{CO})=E^{\text {form }}(\mathrm{CO})+E^{\text {ads }}(\mathrm{CO}) .
$$

The value $E^{\text {ads }}(C)$ is estimated to vary between -500 and $-800 \mathrm{~kJ} / \mathrm{mol}[11]$. However, knowledge of the activation energies enables an estimate of this value, since according to microscopic reversibility

$$
E_{\text {rec }}^{\mathrm{act}}+E(\mathrm{C}+\mathrm{O})=E_{\mathrm{dis}}^{\mathrm{act}}+E(\mathrm{CO}) .
$$

Using the following values $[7,10,14,35]: E^{\text {ads }}(\mathrm{CO})=-120 \mathrm{~kJ} / \mathrm{mol}, E^{\text {form }}(\mathrm{CO})$ $=-1020 \mathrm{~kJ} / \mathrm{mol}, E_{\text {dis }}^{\text {act }}=-150 \mathrm{~kJ} / \mathrm{mol}$, and $E^{\text {ads }}(\mathrm{O})=-400 \mathrm{~kJ} / \mathrm{mol}$, we deduce for $E^{\mathrm{ads}}(\mathrm{C})=-760 \mathrm{~kJ} / \mathrm{mol}$, which is close to the data calculated in ref. [11]. 


\subsection{THE ELEY-RIDEAL MECHANISM OF ATOMIC CARBON RECOMBINATION WITH ADSORBED OXYGEN}

The other type of experiment involves the reaction of adsorbed $O$ with gasphase carbon atoms. Oxygen was adsorbed on a pure $\mathrm{Rh}$ surface by exposing the sample to an oxygen atmosphere $\left(p\left(\mathrm{O}_{2}\right) \approx 1 \times 10^{-7} \mathrm{mbar}\right)$ at $300 \mathrm{~K}$. Saturation of oxygen coverage on the surface was reached within $2 \mathrm{~min}$. Then, the carbon flux was directed to the surface at different temperatures $(T=360-550 \mathrm{~K})$. The kinetics of oxygen depletion was monitored by AES. To avoid the influence of heating to the oxygen coverage on the surface, after oxygen adsorption at $300 \mathrm{~K}$, the sample was heated at approximately $500 \mathrm{~K}$ for about $2 \mathrm{~min}$, which should give about $0.5 \mathrm{ML}$ of oxygen coverage on $\mathrm{Rh}$ [34]. The kinetics of oxygen depletion is shown in fig. 7.

As one can see, the rate is nearly independent of temperature. The oxygen depletion curves can be fitted by an exponential function, with

$$
\begin{aligned}
& \theta_{\mathrm{O}}(t)=\theta_{\mathrm{O}}^{0} \exp \left[-r_{\mathrm{O}}(T) t\right], \\
& r_{\mathrm{O}}(T)=k_{0} \exp \left(-E_{\mathrm{ER}}^{\mathrm{act}} / R T\right) f\left(\nu_{\mathrm{C}}\right) .
\end{aligned}
$$

A number of measurements for the kinetics of oxygen depletion were carried out at different temperatures. This enabled a determination of the activation energy $E_{\mathrm{ER}}^{\text {act }}$,

$$
E_{\mathrm{ER}}^{\text {act }}=4 \pm 3 \mathrm{~kJ} / \mathrm{mol} \text {. }
$$

The results are very different from the earlier discussed Langmuir-Hinshelwood case. The activation energy of the reaction is nearly zero. The explanation is very similar to the Eley-Rideal mechanism discussed by Tully [12]. The large

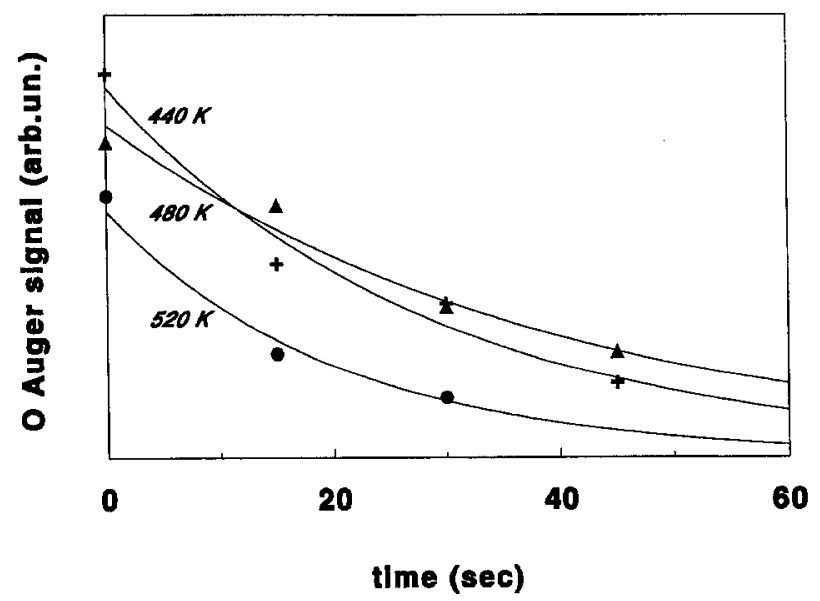

Fig. 7. Kinetics for adsorbed oxygen depletion under an atomic carbon flux $\left(\nu_{\mathrm{C}} \approx 3 \times 10^{13} \mathrm{at} / \mathrm{cm}^{2} \mathrm{~s}\right)$ at different temperatures. The dots are experimental data, the lines are exponential fits. 
exothermicity of $\mathrm{CO}$ formation drives the reaction. The reaction is fast compared to the energy equilibration. CO desorbs instantaneously and most of the energy of the reaction results in translational, vibrational and rotational energy of $\mathrm{CO}$. The absence of a barrier of recombinative adsorption is consistent with the high energy of recombining oxygen and carbon atoms.

This process has some similarities to that in which mobile oxygen atoms are generated upon dissociative oxygen adsorption [36]. Then the energy gain by dissociative adsorption is partially converted to translational energy of the surface oxygen atoms.

\section{Conclusion}

The Langmuir-Hinshelwood reaction path was found under kinetic regime conditions, with equilibration of gas-phase oxygen and adsorbed oxygen and a low rate of adsorbed carbon and adsorbed oxygen recombination. The Eley-Rideal reaction path occurs in the dynamic regime, where the rate of reaction is fast compared to the rate of energy equilibration.

The Langmuir-Hinshelwood experiment provides a route towards the determination of activation energies for recombination and also for dissociation via microreversibility. This may be especially useful when we desire to measure dissociation energies of molecules that are high and are difficult to measure because of competitive desorption.

\section{References}

[1] P. Biloen and W.M.H. Sachtler, Adv. Catal. 30 (1981) 165.

[2] P.C. Ellgen, W.J. Bartley, M.M. Bhasin and T.P. Wilson, Adv. Chem. 178 (1979) 147;

M. Kawai, M. Uda and M. Ichikawa, J. Phys. Chem. 89 (1985) 1654;

V. Ponec, in: New Trends in CO Activation, Studies in Surf. Sci. and Catal., Vol. 64, ed. L. Guczi (Elsevier, Amsterdam, 1991) p. 117.

[3] J.C. Schlatter and K.C. Taylor, J. Catal. 49 (1977) 42; 63 (1980) 53.

[4] B.E. Nieuwenhuys, Surf. Sci. 126(1983) 307.

[5] B.A. Sexton and G.A. Somorjai, J. Catal. 46(1977) 167.

[6] J.T. Yates, E.D. Williams and W.H. Weinberg, Surf. Sci. 91 (1980) 562.

[7] V.V. Gorodetskii and B.E. Nieuwenhuys, Surf. Sci. 105 (1981) 299.

[8] V. Schmatloch and N. Kruse, Surf. Sci. 269/270 (1992) 488.

[9] M. Rebholz, R. Prins and N. Kruse, Surf. Sci. 259 (1991) L797.

[10] A. de Koster and R.A. van Santen, Surf. Sci. 233(1990) 366.

[11] R.A. van Santen and A. de Koster, in: New Trends in CO Activation, Studies in Surf. Sci and Catal., Vol. 64, ed. L. Guczi (Elsevier, Amsterdam, 1991) p. 1.

[12] J.C. Tully, J. Chem. Phys. 73 (1980) 6333.

[13] H. Kang, K.H. Park, S.H. Suck Salk and C.W. Lee, Chem. Phys. Lett. 193 (1992) 104.

[14] K.P. Huber and G. Herzberg, Molecular Spectra and Molecular Structure IV: Constants of Diatomic Molecules (Van Nostrand Reinhold, New York, 1979) p. 158. 
[15] G.G. Low and A.T. Bell, J. Catal. 57 (1979) 397.

[16] F. Solymosi and A. Erdöhelyi, Surf. Sci. 110 (1981) L630;

A. Erdöhelyi and F. Solymosi, J. Catal. 84 (1983) 446.

[17] D.G. Castner, B.A. Sexton and G.A. Somorjai, Surf. Sci. 71 (1978) 519.

[18] P. Finetti, R.G. Agostino, A. Derossi, A. Santoni and R. Rosei, Surf. Sci. 262 (1992) 1.

[19] I. Alstrup, I. Chorkendorff and S. Ulmann, Surf. Sci. 293 (1993) 133.

[20] H. He, J. Nakamura and K. Tanaka, Surf. Sci. 283 (1993) 117.

[21] N.R. Gall, S.N. Mikhailov, E.V. Rut'kov and A.Ya. Tontegode, Surf. Sci. 191 (1987) 185.

[22] M.Yu. Smirnov, N.R. Gall, A.R. Cholach, V.V. Gorodetskii, A.Ya. Tontegode, E.V. Rut'kov and D.Yu. Zemlyanov, Catal. Lett. 8 (1991) 101.

[23] F.L. Hutson, D.E. Ramaker and B.E. Koel, Surf. Sci. 248 (1991) 104.

[24] J.W. Niemantsverdriet and A.D. van Langeveld, Catalysis 1987, Proc. 10th North American Catalysis Society Meeting, ed. J.W. Ward (Elsevier, Amsterdam, 1988) p. 769;

J.W. Niemantsverdriet and A.D. van Langeveld, Fuel 65(1986) 1396.

[25] A.D. van Langeveld, F.C.M.J.M. van Delft and V. Ponec, Surf. Sci. 135(1983) 93.

[26] T.B. Massalski, ed., Binary Alloy Phase Diagrams, Vol. 1 (American Society for Metals, 1986) p. 587.

[27] L.A. DeLouise and N. Winograd, Surf. Sci. 138 (1984) 417.

[28] L.C.A. van den Oetelaar, S.N. Mikhailov and H.H. Brongersma, Nucl. Instr. Meth. B 85 (1984) 420.

[29] N.R. Gall, S.N. Mikhailov, E.V. Rut'kov, A.Ya. Tontegode, Kinet. i Katal. 29 (1988) 1196, in Russian; Kinet. Catal. 29 (1988) 1033, in English.

[30] F.L. Hutson, D.E. Ramaker, B.E. Koel and S.C. Gebhard, Surf. Sci. 248 (1991) 119.

[31] J.E. Houston, D.E. Peebles and D.W. Goodman, J. Vac. Sci. Technol. A 1 (1983) 995.

[32] A.A. Dost, V.R. Dhanak and S. Buckingham, J. Catal. 89 (1984) 159.

[33] D.A. Hickman and L.D. Schmidt, Science 259 (1993) 343.

[34] G. Comelli, V.R. Dhanak, M. Kiskinova, N. Pangher, G. Paolucci, K.C. Prince and R. Rosei, Surf. Sci. 260 (1992) 7.

[35] Handbook of Chemistry and Physics, 72th Ed. (CRCPress, Boca Raton, 1991).

[36] H. Brune, J. Wintterlin, R.J. Behm and G. Ertl, Phys. Rev. Lett. 68 (1992) 624. 